\title{
Estado e terceiro setor na produção do espaço para o turismo de base comunitária na Amazônia paraense: o caso da comunidade ribeirinha Anã no município de Santarém-PA
}

State and Third Sector in the production of space for community-based tourism in Pará Amazon: The Case of the riverfront Anã in the municipality of Santarém-PA

Estado y tercer sector en la producción del espacio para el turismo basado en la comunidad en Pará Amazon: el caso de la orilla del río Ana, en el municipio de Santarém-PA

http://dx.doi.org/10.18472/cvt.16n2.2016.1182

Elcivania de Oliveira Barreto 〈vaniabarreto21@gmail.com >

Secretaria Municipal de Planejamento, Desenvolvimento e Turismo de Santarém, Brasil.

Maria Goretti da Costa Tavares 〈 goretti@ufpa.br >

Professora Associada da Faculdade de Geografia e Cartografia e do Programa de Pós-Graduação em Geografia da Universidade Federal do Pará, UFPA, Brasil.

CRONOLOGIA DO PROCESSO EDITORIAL

Recebimento do artigo: 17-nov-2015

Aceite: 14 -ago-2016

FORMATO PARA CITAÇÃO DESTE ARTIGO

BARRETO, E. O.; TAVARES, M. G. C. Estado e Terceiro Setor na produção do espaço para o turismo de base comunitária na Amazônia paraense: o caso da Comunidade Ribeirinha Anã no município de Santarém-PA. Caderno Virtual de Turismo. Rio de Janeiro, v. 16, n. 2, p. 211-231, ago. 2016.

REALIZAÇÃO

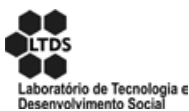

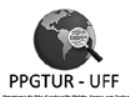

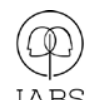

APOIO INSTITUCIONAL

EDIÇÃO

PATROCÍNIO

COPPE

UFR] 


\section{RESUMO}

O presente artigo apresenta parte dos resultados de nossa dissertação de mestrado, busca assim, analisar o papel do Estado e do Terceiro Setor na produção do espaço para o Turismo de Base Comunitária - TBC, na Amazônia paraense, particularmente na comunidade ribeirinha de Anã, localizada no município de Santarém, no oeste do estado do Pará. Considerando o TBC como um contraponto às formas convencionais de turismo, ele foi introduzido no território da comunidade ribeirinha de Anã no ano de 2008 por intermédio da ONG Projeto Saúde e Alegria - PSA. Além das pesquisas bibliográficas, realizou-se pesquisa documental e de campo. Para a realização da pesquisa de campo, elaboramos e utilizamos roteiros de entrevistas específicos para cada sujeito da pesquisa, sendo estes agrupados da seguinte forma: representante da ONG PSA, ex-secretários de Turismo do município de Santarém e comunitários de Anã. O estudo apontou que o Estado, níveis municipal e estadual, em relação ao TBC, mostra-se praticamente ausente, não sendo possível identificar nenhuma ação voltada para o desenvolvimento do TBC. O Terceiro Setor, identificado pela presença da ONG PSA, teve e tem papel fundamental, atuando hegemonicamente no desenvolvimento do TBC no território da comunidade.

Palavras-chave: Estado. Terceiro Setor. Turismo de Base Comunitária. Comunidade Ribeirinha de Anã.

\section{ABSTRACT}

This article presents part of the results of our dissertation, seeking thereby to analyze the role of the state and the third sector in the production of space for community-based tourism - CBT, in Pará Amazon, particularly in the riverside community of Anã located in the municipality of Santarém in western of Pará state. Considering the CBT as a counterpoint to conventional forms of tourism, it has been introduced within the Anã riverside community in 2008 through the NGO Projeto Saúde e Alegria - PSA. In addition to literature searches, perform desk and field research. To carry out field research, we develop and use specific interviews scripts for each research subject, which are grouped as follows, representative of the NGO PSA, former Secretary of Municipality of Santarem Tourism and Community Anã. The study found that state, municipal and state levels, compared to the CBT shows practically absent, it is not possible to identify any action geared to the development of CBT. The third sector, identified by the presence of NGO PSA, and has had key role, acting hegemonic in the development of CBT within the community.

Keywords: State. Third Sector. Community Based Tourism. Riverside community of Anã.

\section{RESUMEN}

Este artículo presenta parte de los resultados de nuestra disertación, buscando con ello analizar el papel del Estado y el tercero sector en la producción del espacio para el turismo basado en la comunidad - por confirmar, en Pará Amazonia, especialmente en la comunidad ribereña de Anã ubicada, en el municipio de Santarém, en el estado de Pará. Considerando la TBC como contrapunto a las formas convencionales de turismo, se ha introducido dentro de la comunidad ribereña de Anã en 2008 a través de la ONG Projeto Saúde e Alegria - PSA. Además de búsquedas bibliográficas, realice escritorio y campo de investigación. Para llevar a cabo la investigación de campo, desarrollamos y utilizamos scripts de entrevistas específicas para cada sujeto de investigación, que se agrupan de la siguiente manera, representante de la ONG de PSA, los ex secretarios de Turismo de Santarem y Comunidad de Anã. El estudio encontró que los niveles estatal, municipal y estatal, frente a la TBC muestra prácticamente ausente, no es posible identificar cualquier acción orientada al desarrollo de TBC. El tercero sector, identificado por la presencia de ONG de PSA, y ha tenido papel fundamental, actuando hegemónico en el desarrollo del TBC en la comunidad.

Palabras clave: Estado. Tercero Setor. Turismo basado em la comunidade. Comunidad ribereña de Anã. 


\section{INTRODUÇÃO}

Levando em consideração que o turismo consome elementarmente o espaço, tendo este como seu principal objeto de consumo (CRUZ, 2002), este artigo desenvolveu-se com base na ciência geográfica, que nos deu um suporte teórico-metodológico para analisarmos a experiência de Turismo de Base Comunitária - TBC desenvolvida na comunidade ribeirinha de Anã, a qual está dentro dos limites da Reserva Extrativista Tapajós-Arapiuns, localizada no município de Santarém, estado do Pará.

$\mathrm{O}$ TBC tem sido apontado como um contraponto às formas convencionais de turismo, uma vez que se privilegia a participação da comunidade local no processo de planejamento, execução e monitoramento da atividade, além do que implica os momentos de vivência, experiências de vida compartilhadas entre visitantes e visitados.

O TBC tem sido desenvolvido na comunidade de Anã desde o ano de 2008, por intermédio da ONG Projeto Saúde e Alegria - PSA, que atua no município de Santarém desde a década de 1980 (século XX) com projetos voltados para a área da saúde.

Partindo do pressuposto que o TBC trata-se de contrarracionalidade hegemônica ante as formas convencionais de turismo, mas que também se apropria e produz espaço, implicando assim em um processo contraditório e conflituoso devido aos agentes produtores deste, questionou-se: Qual o papel do Estado e da ONG PSA na produção do espaço para o turismo de base comunitária em Anã?

Diante disso, neste artigo, buscou-se analisar o papel do Estado e do Terceiro Setor na produção do espaço para o TBC na comunidade ribeirinha de Anã. Para tanto, buscamos inicialmente caracterizar a experiência de TBC desenvolvida em Anã, para em seguida identificarmos o papel do Estado e da ONG PSA para o desenvolvimento dessa prática na comunidade. Para embasar nossas análises, utilizou-se o conceito uso do território de Santos e Silveira (2008), além disso, Santos (2009; 2012a; 2012b; 2012c); Harvey $(2013 ;$ 2005) e Mariano (2007) nos auxiliam em nossa reflexão sobre o Estado. Para auxiliar em nossa reflexão sobre Terceiro Setor, utilizamos Coutinho (2004); Monte (2002) e Landim (2002).

Assim, este artigo apresenta inicialmente uma breve reflexão sobre os conceitos de Turismo de Base Comunitária, Estado e Terceiro Setor, para em seguida discorrermos sobre a experiência de TBC desenvolvida em Anã, apresentando os resultados obtidos durante a pesquisa.

\section{TURISMO DE BASE COMUNITÁRIA: UMA BREVE ABORDAGEM}

No que se refere ao turismo de base comunitária - TBC, constatamos que ainda existe pouca produção teórica, no entanto, tal prática tem despertado o interesse de vários estudiosos, principalmente ligados à área da geografia, incitando a produção de pesquisas em lugares que vêm desenvolvendo essa modalidade de turismo.

Diante das várias experiências de TBC no País e no mundo, diversificam-se também as terminologias e conceitos sobre tal modalidade, o que não quer dizer que seja um problema, mas sim um desafio para extrair de tais experiências suas especificidades e suas contribuições para a formulação de um aporte teórico sobre o TBC, bem como a formulação de políticas públicas de turismo que vislumbrem justamente 
o olhar, a inserção da população local. Para tanto não se pode falar em modelos ou quaisquer outras formas simplificadoras. A diversidade de contextos, histórias, lugares e personagens fazem de cada uma das iniciativas autoproclamadas "comunitárias" únicas. Tentar compreender essa diversidade e extrair ensinamentos que possam subsidiar a formulação de políticas públicas é sem dúvida um grande desafio (BARTHOLO; SANSOLO; BURSZTYN, 2009, p. 16).

Levando em consideração a diversidade de experiências, identificamos algumas denominações que essa modalidade assume tanto na práxis como na literatura, as quais sejam: turismo comunitário, ecoturismo de base comunitária, turismo responsável, turismo rural comunitário, turismo justo, turismo solidário, entre outras. Sendo assim apresentaremos a seguir reflexões de alguns autores que têm contribuído para a construção e o fortalecimento de um aporte teórico em torno da temática.

Cito inicialmente o conceito de ecoturismo de base comunitária apresentado por Mitraud (2003), o qual parte de uma perspectiva de turismo responsável. Sendo assim, esse seria o tipo de "turismo realizado em áreas naturais, sendo determinado e controlado pelas comunidades locais, que gera benefícios predominantemente para essas e para as áreas relevantes para a conservação da biodiversidade" (MITRAUD, 2003, p. 23). Vale ressaltar que esse conceito se encontra no Manual de Ecoturismo de Base Comunitária elaborado pela WWF no ano de 2003. Esse manual apresenta algumas possíveis metodologias de desenvolvimento do ecoturismo no Brasil, uma vez que se vivenciava um período de desalento com a atividade turística tendo em vista os seus impactos negativos acarretados principalmente às áreas naturais e às populações residentes.

Utilizando a mesma terminologia, "ecoturismo de base comunitária", a ONG Ceaps/ Projeto Saúde e Alegria refere-se à prática como uma nova forma de gerir o turismo com ênfase no ser humano e nas relações com o outro. Visando a geração de renda em comunidades ribeirinhas da região, a ONG propôs o projeto Ecoturismo de Base Comunitária, que parte de uma perspectiva de turismo que

[...] propõe um modelo de desenvolvimento que privilegie o ser humano, que garanta condições de vida digna a todos os cidadãos, centrado em uma cultura de cooperação, parceria e solidariedade. [...] pretendendo ser antes de tudo um momento de encontro entre pessoas e culturas diferentes e este elemento precisa ser resgatado com muita ênfase, com todas suas implicações, para sair da lógica restrita e mercantilista do turismo de massa (ONG PROJETO SAÚDE E ALEGRIA, 2011).

Observa-se, nesse sentido, que o conceito apresentado pela ONG enfatiza uma contraposição ao turismo de massa, uma vez que privilegia as experiências vivenciadas tanto pelo residente quanto pelo visitante, uma experiência no e com o lugar, portanto, busca-se não a fragmentação dos lugares, tampouco a exclusão do feio, muito menos afastar o turista do pobre, do usual, conforme ressalta Carlos ao tratar do turismo contemporâneo, mas propor uma nova forma de turismo que valorize o lugar, as relações existentes, as experiências vividas nesse lugar.

[...] nós vendemos o mundo como ele é, então não queremos mostrar um lado fantástico, do lugar que não é fantástico, nós mostramos o lado bom e o lado ruim, a gente tem que conhecer os problemas na Amazônia, temos que conhecer as dificuldades de uma comunidade isolada de tudo ribeirinha, como ver os lados positivos, alegres e culturalmente humanos dessas pessoas [...] (Entrevista concedida pelo coordenador do projeto de ecoturismo de base comunitária da ONG Saúde e Alegria, junho de 2011).

No âmbito do Estado, mais precisamente do Ministério do Turismo, órgão oficial do Turismo no Brasil, o turismo de base comunitária, denominado ainda de solidário, de conservação, entre outras denominações, se configura como: 
modelo alternativo de desenvolvimento turístico, baseado na autogestão, no associativismo/cooperativismo, na valorização da cultura local e, principalmente, no protagonismo das comunidades locais, visando à apropriação por parte destas dos benefícios advindos do desenvolvimento da atividade turística (BRASIL, MTUR, 2008).

Convém destacar o conceito apresentado pela Rede Cearense de Turismo Comunitário - Rede Tucum, a qual utiliza a terminologia turismo comunitário, e diz que este nasce da percepção das próprias comunidades em relação ao turismo que, insatisfeitas com um modelo de desenvolvimento turístico pautado na concentração de renda e na geração de problemas socioambientais, passaram a requerer para si uma autonomia ante a atividade turística em seus territórios, redesenhando assim um turismo que vai "na contramão do convencional, pois a população local passa a ter o controle efetivo do planejamento das atividades e pela gestão das infraestruturas e serviços turísticos" (REDE TUCUM, 2013).

No site da Rede Tucum são apresentados ainda princípios e diretrizes que regem o turismo comunitário no Ceará, quais sejam:

1. As atividades de turismo são desenvolvidas por grupos organizados e os projetos são coletivos, de base familiar;

2. O turismo se integra à dinâmica produtiva local, sem substituir as atividades econômicas tradicionais;

3. O planejamento e a gestão das atividades são de responsabilidade da organização comunitária local;

4. O turismo comunitário baseia-se na ética e na solidariedade para estabelecer as relações comerciais e de intercâmbio entre a comunidade e os visitantes;

5. O turismo comunitário promove a geração e a distribuição equitativa da renda na comunidade;

6. O turismo comunitário fundamenta-se na diversidade de culturas e tradições, promovendo a valorização da produção, da cultura e das identidades locais;

7. O turismo comunitário promove o relacionamento direto e constante entre grupos que também desenvolvem a experiência de um turismo diferente, estabelecendo relações de cooperação e parceria entre si;

8. O turismo comunitário fundamenta-se na construção de uma relação entre sociedade, cultura e natureza que busque a sustentabilidade socioambiental (REDE TUCUM, 2013).

Tais princípios e diretrizes nos remetem ao conceito de turismo comunitário elaborado por Coriolano, que tem desenvolvido de forma exponencial estudos sobre a temática em comunidades litorâneas no estado do Ceará.

O turismo comunitário é aquele em que as comunidades de forma associativa organizam arranjos produtivos locais, possuindo o controle efetivo das terras e das atividades econômicas associadas à exploração do turismo. Nele o turista é levado a interagir com o lugar e com as famílias residentes, seja de pescadores, ribeirinhos, pantaneiros ou de índios (CORIOLANO, 2009, p. 282).

Para Maldonado (2009), o Turismo Rural Comunitário, terminologia utilizada pelo referido autor, surge principalmente como uma forma de resistência das populações locais em seus territórios, uma forma de resistir às intensas transformações impostas pelo processo de globalização ao seu lugar.

O turismo de base comunitária, nesse sentido, "deve favorecer a coesão e o laço social e o sentido coletivo de vida em sociedade, e que por esta via, promoverá a qualidade de vida, o sentido de inclusão, a valorização da cultura local e o sentimento de pertencimento" (IRVING, 2009, p. 112).

O turismo de base comunitária nos permite desta forma repensar o sentido do lugar, partindo de uma reflexão

'da maneira como as pessoas vivem nos lugares onde residem ou os que visitam, deles extraindo uma experiência' (CLAVAL, 2001, p. 46 apud, MARANDOLA, p. 78).

O turismo de base comunitária, segundo Bartholo (2009), invoca um sentido de proximidade, o qual dialoga com o sentido do lugar heiddegeriano, uma vez que “[...] o lugar heideggeriano encaminha ao en- 
contro face a face no vigor da proximidade. Nele a centralidade do encontro face a face não é meramente topológica" (BARTHOLO, 2009 p. 45). Diante disso, Bartholo (2009) discorre sobre o sentido de proximidade relacionando-o com as ideias da relação Eu-tu de Martin Buber, levando em conta que "a pessoa da relação Eu-Tu é o suporte relacional que permite fazer da alteridade uma presença, em uma possibilidade relacional que se estende para além do campo do inter-humano". O resgate do sentido de proximidade se dá em decorrência da própria negação do sentido de proximidade que se tem observado nos dias atuais, no contexto de uma sociedade que vive em "tempos líquidos", no qual a valorização da relação Eu-Isso, se dá em detrimento da Eu-tu. Vale frisar que na relação Eu-Isso "não há lugar para proximidades vinculares, que lhe permanecem uma exterioridade. Ela não conhece encontros face a face [...]" (BARTHOLO, 2009, p. 51).

Portanto, o turismo de base comunitária permite um sentido de proximidade, que se concretiza nas experiências vividas e compartilhadas entre nativos e viajantes, ambos se permitem "uma atitude dialógica, o que significa a abertura para primordialmente falar com alguém, não de alguém ou alguma coisa" (BARTHOLO, 2009 p. 52).

Isso demonstra o diferencial do turismo de base comunitária das demais modalidades de turismo que existem, em que se tem como foco não a dimensão econômica, mas a dimensão social, circunscrita em uma perspectiva de maior autonomia das populações envolvidas no processo, propiciando assim o aumento da justiça social e da qualidade de vida, consolidando de fato um desenvolvimento territorial pleno.

Para tanto, vale destacar Irving (2009) ao elencar as premissas para o turismo de base comunitária, como forma de propor uma reflexão em torno deste, que possa vir a ultrapassar o sentido de "comunitário" e principalmente "comunidade", que na maioria das vezes são remetidos, ou tidos como sinônimos de pessoas carentes, de baixa renda, e por assim também exclusos das políticas de Estado, e/ou relegados a segundo plano em tais políticas:

- Base endógena da iniciativa e desenvolvimento local;

- Participação e protagonismo social no planejamento, implementação e avaliação de projetos turísticos;

- Escala limitada e impactos sociais e ambientais controlados;

- Geração de benefícios diretos à população local;

- Afirmação cultural e interculturalidade;

- O "encontro" como condição essencial.

Tais premissas revelam a importância da população local nesse processo, em que não será o mercado a ditar as regras de o quê, como implementar o turismo em seu local. Trata-se de fato da presença dos atores locais durante todo o processo do planejamento da atividade até mesmo na execução desta, promovendo o desenvolvimento local a partir da iniciativa própria do local, firmando-os em seu território, em sua identidade, e fazendo do "encontro" com o turista o seu principal "objetivo", que deve corresponder:

no compromisso ético, de respeito, e engajamento de quem está de quem vem e o intercâmbio real entre os sujeitos que recebem e os que são recebidos e destes, com o ambiente no qual interagem (...) nesse sentido, atores locais e turistas são, simultaneamente, agentes, sujeitos e objetos no processo (IRVING, 2009, p. 116-117). 
Nessa nova perspectiva de turismo, também é revelado um novo perfil do turista, pois nesse caso não é o turista convencional que procura por experiências como essas, mas são turistas que, tomados de uma percepção de mundo diferenciada, em que se volta a conhecer e se mergulhar no outro, em um modo diferente, que lhes permita vivenciar costumes, modos de vida totalmente diferentes do seu, mas que também se permita transmitir suas experiências enquanto não pertencente ao local visitado. Esse novo perfil de turista revela a importância dessas populações excluídas pelo turismo convencional, mas que possibilitam a inserção delas em um segmento em que não é a lógica nem o "tempo" do mercado que prevalece, mas a lógica, o "tempo" de comunidades seja tradicional ou não, que estabelecem e se firmam com uma nova proposta de turismo, que faz do encontro entre turistas e visitados, um processo, uma descoberta, crítica e reinvenção de uma nova realidade (IRVING, 2009).

Conforme podemos observar, há uma gama de denominações e características que em um esforço em conjunto buscam designar o turismo de base comunitária. Contudo, fez-se necessário optarmos por uma terminologia, a qual conduziu-nos na análise do nosso objeto de estudo.

Assim, utilizamo-nos, neste trabalho, da terminologia turismo de base comunitária, assim como nos assentamos nas premissas do TBC propostas por Irving (2009), as quais nos permitiram refletir o TBC enquanto possibilidade de uma comunidade, seja esta tradicional, ou não, firmar-se em seu território; direcionar o uso do seu território seja este para o turismo ou não; ter autonomia no processo de planejamento, execução e monitoramento da atividade; e de proporcionar um desenvolvimento, que corresponda de fato a uma mudança social positiva; tornando-os de fato verdadeiros cidadãos.

Mas, ainda trataremos o TBC como um contraponto ao turismo convencional, utilizando Santos (2012b), buscou-se analisá-lo como uma contrarracionalidade hegemônica, na qual se busca a essência nas relações entre os sujeitos, essa busca, que se configura como "um movimento sem fim que inclui o sujeito em um processo dialético e o restitui a si mesmo", e que faz restaurar a individualidade adormecida em um período histórico em que o "êxito" é norma essencial da vida.

\section{REFLETINDO SOBRE O PAPEL DO ESTADO NO PERÍODO HISTÓRICO ATUAL}

Refletir sobre o papel do Estado no período histórico atual é reconhecer que estamos diante de um novo comportamento do Estado, movido, sobretudo pela necessidade de expansão do modo de produção capitalista, que necessita sempre de novos espaços para consolidar-se. Mediante o exposto, convém ressaltar Harvey (2013, p. 79), o qual nos lembra que (...) "a formação do Estado em associação com o surgimento da constitucionalidade burguesa tem sido, por conseguinte, caraterísticas cruciais da longa geografia histórica do capitalismo".

Portanto, o período histórico atual, movido pela égide da globalização, que submete os Estados a desafios de inserção e superação das vicissitudes do mercado mundial, sendo o ditador das regras o sistema financeiro internacional, modifica consideravelmente o papel do Estado, o qual passa a funcionar em consonância com as políticas empresariais (SANTOS, 1998). Seguindo o mesmo pensamento, Herz (1999, apud, MARIANO, 2007, p. 127), diz que: 
O Estado tradicional estaria dando lugar a uma nova forma ou lógica de Estado na qual as decisões políticas são permeadas e influenciadas por redes transnacionais intergovernamentais. Em consequência, o papel do Estado transforma-se: é crescentemente um instrumento de adaptação das políticas domésticas à realidade internacional e, portanto, de decisões tomadas em outras esferas de poder, sejam elas regionais, transnacionais ou internacionais.

Conquanto, aponta Harvey (2013, p. 79), "os capitalistas não requererem absolutamente esse arcabouço para funcionar, mas na ausência dele encontram maiores riscos”. Até porque, é por meio das ações estatais que a atividade capitalista poderá encontrar as melhores condições para poder se instalar e se desenvolver em determinada porção do território.

É possível perceber esse cenário principalmente a partir de 1980, com a instauração de uma intensa política de desestatização, dando início à "era das privatizações", na qual as empresas públicas passaram a pertencer às iniciativas privadas, e até mesmo corporações internacionais; nutre-se o mercado internacional por meio de prerrogativas que lhes possibilitam cada vez mais a sua expansão, por meio de políticas estatais. Paralelo a isso, assiste-se, cada vez menos o Estado preocupado com a elaboração e implementação de políticas sociais, pois o recurso público passa a ser utilizado intensivamente para melhorias e ampliação de infraestruturas que possam servir ao capital, dotando o território (porções do território) de sistemas de engenharia, tornando-o assim mais fluido, contudo cada vez mais corporativo e fragmentado, estabelecendo, doravante, um uso diferencial do território.

Esse uso diferencial do território se realiza, conforme Santos e Silveira (2008), na disputa pelos lugares luminosos e lugares opacos entre empresas com diferentes graus de modernidade capitalista ou organizacional. Nessa disputa, as empresas mais hegemônicas reivindicam os lugares mais luminosos, em virtude principalmente de sua densidade técnica que dará melhores condições às atividades econômicas que serão desenvolvidas, além, é claro, do lugar, onde encontrarão a mais-valia desejada, para que se obtenha mais lucro.

Apesar do papel de grande intermediário, entre o modo de produção em escala internacional e a sociedade nacional, não se pode considerar o Estado como um intermediário passivo (SANTOS, 2012c), pois,

[...] ao acolher os feixes de influências, ele os deforma, modificando sua importância, sua direção e, mesmo sua natureza. Isso significa que a reorganização de um subespaço sob a influência de forças externas depende sempre do papel que o Estado exerce (SANTOS, 2012c, p. 226).

Presencia-se a cada dia deste período hodierno, que as ações do Estado voltam-se fundamentalmente para a produção do espaço para atender, conforme já enfatizamos, aos interesses de uma lógica global, portanto, se por um lado as ações do Estado se dão de forma efetiva, por outro lado, no que tange principalmente às suas funções sociais e políticas, observa-se um encolhimento de suas ações (SANTOS, 2009c).

Sendo assim, podemos considerar Todesco (2010) ao tratar sobre o papel do Estado na organização do espaço para o turismo no Vale do Ribeira, classificando sua atuação da seguinte forma: "Presença ausente do Estado" e "Ausência presente do Estado", classificação esta que sinaliza bem a atuação do Estado no período histórico atual. O primeiro corresponde à presença do Estado em dada fração do território, por meio de planos, programas e projetos, entre outras ações, contudo, ineficientes para proporcionar um resultado efetivo diante da demanda almejada.

O segundo refere-se à modificação da atuação do Estado em dada fração do território, no qual passa a não mais implementar ações diretas sobre tal, porém, passa a delegá-las a outros sujeitos, como no caso o 
Terceiro Setor, este que em diversos momentos será financiado pelo próprio Estado. É assim que o Estado vai se configurando como mínimo em território nacional, em um primeiro momento mostrando sua ineficiência quanto à execução de suas ações, tornando-se presente, mas ausente e, por outro, delegando e financiando ações de outras instituições não públicas, como no caso instituições pertencentes ao Terceiro Setor, para realizar suas funções, mostrando-se ausente mas presente. É assim que vai se configurando as (in) ações do Estado no território nacional, principalmente o que se refere às questões sociais.

Restringindo suas funções políticas e sociais, o Estado amplia consideravelmente suas funções para o mercado, mostrando políticas cada vez mais eficientes ao beneficio deste, principalmente no que se refere à instalação ou requalificação de fixos e fluxos que darão suporte a sua ampliação e fortalecimento. Contudo, nem todo território interessa ao capital, em se tratando do Brasil, observa-se como o território é descontínuo em termos de densidade de objetos e ações.

E isso é algo histórico, que configura continuamente um agravo das diferenças territoriais, onde tais diferenças são assinaladas principalmente pelo uso do território pelo mercado e pelo Estado, os quais, em um jogo dialético, serão determinantes para o uso de uma dada porção do território em determinado período, dotando-a de valor ou não, de acordo com interesses externos ao território.

É dessa forma que o turismo, enquanto atividade econômica, foi sendo incorporado ao território brasileiro; se levarmos em conta a sua ocorrência de forma efetiva, podemos considerar apenas frações do território, já que tanto o Estado quanto o mercado selecionam apenas frações do território brasileiro para $\mathrm{o}$ investimento em tal setor.

Diante disso, criou-se uma racionalidade para o desenvolvimento do turismo no Brasil, em que prevalece o imperativo do mercado, principalmente quando se estimula a construção de destinos turísticos como simulacros, visando simplesmente atender a um mercado consumidor, desvirtuando o cotidiano e transformando a imagem do lugar.

\section{REFLEXÕES SOBRE O TERCEIRO SETOR NO PERÍODO HISTÓRICO ATUAL}

Como vimos anteriormente, a racionalidade hegemônica que passa a predominar em frações do território faz emergir as contrarracionalidades hegemônicas, que em uma tentativa de sobrevivência, mediante a racionalidade hegemônica produzida no espaço, passa a desenvolver possibilidades de se ajustar enquanto sujeito do processo de organização do território. Veremos a seguir como o Terceiro Setor surge no Brasil, e como ao longo de dois períodos históricos tem reformulado seu perfil, seja pela necessidade ou seja impulsionado a fazê-lo.

Antes, contudo, é necessário saber que o termo "Terceiro Setor" é proveniente dos Estados Unidos, traduzido da expressão em inglês Third Sector e que no Brasil ganhou novos contornos, principalmente a partir da democratização do Estado brasileiro no final da década de 80 do século XX, e que faz emergir um novo ator no cenário nacional, e que se consolida na década de 90 do mesmo século como principal mecanismo de alcance de políticas públicas sociais pela população pobre brasileira. 
Dessa forma já se pode identificar que o Terceiro Setor, apesar de incorporar algumas caraterísticas do Primeiro Setor (Estado) e do Segundo Setor (Mercado), não corresponde a nenhum dos dois setores, por mais que as atividades desenvolvidas por ele caracterizem-se como privadas, os seus objetivos são públicos. De acordo com Monte (2002, p. 70), "tal hibridização permite a defesa da existência de uma esfera pública não estatal, cuja importância está na capacidade de gerar dividendos sociais”.

O Terceiro Setor no Brasil surgiu, segundo Monte (2002), por volta da década de 70 e 80 do século XX, motivado pela necessidade de defesa dos direitos sociais no período da ditadura militar, e sua expansão e consolidação no território brasileiro ocorreram em decorrência de vários fatores, entre os quais destaca:

a inoperância da máquina estatal em promover condições mínimas de sustentabilidade social a uma classe de indivíduos excluída; o processo de globalização, que por meio do modelo capitalista de extinguir postos de trabalho e fechou empresas e o fim do regime militar no país (MONTE, 2002, p. ).

É possível ainda identificar outras nomenclaturas relacionadas ao Terceiro Setor, entre as quais destaca-se Organizações Não Governamentais - ONG, a qual popularizou-se no cenário nacional. Assim, enquanto nomenclatura para instituições que se encontram com esse formato, adotaremos a terminologia ONG neste trabalho.

Segundo Landim (2002), a nomenclatura ONG foi utilizada pela primeira vez em 1940, pelas Nações Unidas - ONU. Era um termo que com frequência aparecia em seus documentos para designar "um universo bastante amplo e vago de organizações com as quais a ONU poderia estabelecer consultorias".

Inicialmente, ONGs correspondiam, no Brasil, principalmente às organizações de cooperação internacional (COUTINHO, 2004), formadas geralmente pelas Igrejas católicas e protestantes, organizações de solidariedade, ou governo de vários países, as quais direcionavam suas ações a organizações e movimentos sociais, visando a democratização do País.

As ONGs de defesa de direitos, criadas nas décadas de 1970 e 1980, em geral, desenvolviam um trabalho na base da sociedade, que visava a democratização e a ampliação de direitos no país, em oposição a um Estado militar autoritário e violador de direitos. O formato associativo foi a expressão institucional encontrada para contribuir para a construção de um Estado democrático de direitos e de uma sociedade multicultural, livre de seculares estruturas de poder, dominação e desigualdade. (ABONG, p. 13).

Com a democratização do País no final da década de 1980, e com a instalação de uma economia neoliberal no Brasil a partir de 1990, há uma consolidação desse setor no País. No entanto, passam a atuar com uma lógica, com ações políticas diferentes das dos anos de 1970 e 1980. Se naquele período suas ações estavam relacionadas essencialmente aos movimentos sociais, em uma luta contra o Estado, doravante, as ONGs passam a buscar parcerias com o próprio Estado, uma vez que como ressaltado em nossa discussão anterior sobre este, a partir da década de 90 do século XX, torna-se ineficiente na elaboração e na execução das políticas sociais do País. Além do Estado, tais organizações passam também a estreitar relações com as empresas privadas. É dessa forma que vão se estruturando no cenário nacional e firmam-se como instituições cidadãs e sem fins lucrativos.

De acordo com Coutinho (2001, p. 58), as ONGs iniciam a partir da década de 1990 uma nova trajetória, com um novo perfil, o qual se configura como um "perfil de filantropia empresarial", passando a manter relações estreitas com o Banco Mundial e com as agências financiadoras ligadas ao grande capital, como o caso das fundações Ford, Rockfeller, Kellog, Mac Arthur, entre outras. 
Se na década de 1970 os objetivos dessas ONGs baseavam-se na politização dos movimentos sociais, em 1990 os objetivos passam a incorporar lemas como desenvolvimento autossustentável (COUTINHO, 2001).

A década de 1990 foi, de acordo com Coutinho (2001), fundamental para a popularização do termo ONG, bem como para sua consolidação no cenário nacional. Contudo, a autora diz que houve uma divisão de tais instituições, as quais se identificam, ou melhor, se imaginam em um campo progressista, e há aquelas ONGs que colaboram com a política neoliberal, dessa forma pode-se dizer que, acompanhado da reestruturação do Estado, veio também uma ruptura dos objetivos unos das ONGs no Brasil: algumas ainda permaneceram com o ideário de desenvolver ações que incitam a busca pelos direitos sociais e políticos, e outras não, que seguiram as regras impostas pela economia neoliberal.

\footnotetext{
O impacto substantivo de suas ações converge para desviar 'o povo da luta de classes para formas inofensivas e ineficientes de colaboração com os seus opressores' (1999:41). Elas despolitizam e desmobilizam os pobres com suas ações focadas na 'autoajuda'. Debruçam sobre temas como 'excluídos', 'discriminação racial, 'relações de gênero' sem ir além do sintoma superficial, para engajar o sistema social que produz essas condições. Incorporando os pobres à economia neoliberal através da simples 'ação voluntária privada', as ONGs geram um mundo político onde a aparência da solidariedade e da ação social disfarça a conformidade conservadora com a estrutura de poder internacional e nacional (PETRAS, 1999).
}

Diante disso, é preciso traçar uma reflexão do real papel desse setor, uma vez que este, como menciona Neder (1998), não é governo, nem mercado, mas sim uma esfera pública não estatal e não mercantil, ocupada com a superação da exclusão social. Porém, é uma reflexão que exige um grande esforço de análise, principalmente quando nos deparamos com a diversidade de ONGs, com os mais distintos objetivos, que revelam por si só, "um universo bastante complexo, diverso, dinâmico e desigual, e instituir-se como não governamental não garante uma concepção pronta nem encerrada” (ABONG, 2010).

\section{CARACTERIZAÇÃO DO TURISMO DE BASE COMUNITÁRIA EM ANÃ: ANÁLISE DO PAPEL DA ONG PROJETO SAÚDE E ALEGRIA E DO ESTADO}

A comunidade Anã está situada à margem direita do Rio Arapiuns, na Reserva Extrativista Tapajós-Arapiuns, a cerca de quatro horas de navegação de Santarém, sendo que o acesso à comunidade se dá exclusivamente por via fluvial.

Ocupando uma área de 1.937 hectares, o território de Anã é recortado por diversos igarapés (ONG PROJETO SAÚDE E ALEGRIA, 2012); e assim como nas demais comunidades pertencentes à Reserva Extrativista Tapajós-Arapiuns, o clima predominante em Anã é o equatorial continental megatérmico úmido da Amazônia Central, que tem como uma de suas características a associação do calor elevado (temperaturas médias anuais entre $26^{\circ} \mathrm{C}$ e $28^{\circ} \mathrm{C}$ ) com umidade alta (valores médios anuais entre $80 \%$ a 85\%) (ICMBIO, 2014). Anã apresenta ainda um solo bastante arenoso, de origem fluvial e uma vegetação composta de capoeiras e matas secundárias, resultado da exploração madeireira e da agricultura de corte e queima (ONG PROJETO SAÚDE E ALEGRIA, 2013).

No ano de 2014 havia na comunidade 94 famílias, com uma população aproximada de 480 pessoas, as quais mantêm suas residências concentradas às margens do Rio Arapiuns. 
A relação da comunidade com o turismo de base comunitária se deu mediante a firmação da atuação da própria ONG Projeto Saúde e Alegria - PSA na comunidade, sendo este parte do programa "empreendimentos sustentáveis", projeto que se concretizou a partir do ano de 2008. Contudo, anteriormente, a ONG já havia organizado viagens a algumas comunidades ribeirinhas da região com o objetivo inicial de facilitar e mediar a interação entre visitantes e comunidades ribeirinhas mediante a prática constante de receber parceiros e financiadores para viagens de trabalho, esta que teve início ainda no ano de 1987. No ano de 2001, a ONG PSA organizou em parceria com o Projeto Bagagem uma expedição pelas comunidades ribeirinhas de Santarém, o qual se denominou Roteiro Amazônia Ribeirinha, que também deu origem à ONG Projeto Bagagem.

Essa experiência com o Projeto Bagagem foi o marco inicial para o desenvolvimento de outros roteiros pela ONG PSA, não somente com o Projeto Bagagem, mas com outros parceiros, outras instituições, como World Learning Brazil, Ambiental Expedições, I-To-I / IkoPoram. Além dessas viagens, a ONG PSA ainda tem organizado viagens demandadas pelos seus parceiros financiadores, com a finalidade de levá-los a conhecer os projetos desenvolvidos pela ONG nas comunidades.

Diante disso, e com a finalidade de fomentar e consolidar o turismo como uma alternativa de geração de renda para as comunidades ribeirinhas do município de Santarém, a ONG PSA elaborou no ano de 2008, um projeto intitulado "Ecoturismo de Base Comunitária no Polo Tapajós", o qual fora submetido ao Ministério do Turismo para concorrer à obtenção de financiamento disposto através do Edital n. 001/2008 do MTur.

É nesse contexto que a comunidade ribeirinha de Anã envolveu-se com o projeto de turismo de base comunitária desenvolvido pela ONG PSA. Esse projeto inicial contemplou quatro comunidades ribeirinhas do município de Santarém, entre as quais Anã. A seleção das comunidades para participação no projeto foi feita pela ONG PSA. Contudo, era uma escolha que dependia principalmente do próprio interesse das comunidades em participar, e este foi um dos pontos avaliados pela ONG no momento em que esta levava a proposta às comunidades.

Vale mencionar que não foi por esse projeto de turismo de base comunitária coordenada pela ONG PSA que a comunidade de Anã "conheceu" o turismo. Anteriormente ao projeto desenvolvido pela ONG, Anã já havia recebido visitas de pessoas de outros estados e países, mas Anã servira apenas de passagem para outras comunidades. E mesmo quando as pessoas se locomoviam até Anã para conhecer os projetos que desenvolvia, como o projeto de criação de peixes, o projeto de manejo de abelhas, entre outros, os comunitários sempre eram surpreendidos, já que em momento algum recebiam comunicados antecipados sobre as visitas previstas à comunidade; assim não fora gerada nenhuma renda pelos visitantes à comunidade, nem pelas agências de turismo que intermediavam a ida dos visitantes, a renda gerada era apenas aos comunitários que comercializavam seus produtos aos visitantes.

Foi justamente esse fato, essa insatisfação por parte dos comunitários de Anã, que os motivou a buscar mais esclarecimentos sobre o turismo, assim como a buscar capacitação, como o curso de guia de turismo comentado anteriormente, para justamente começarem a implementar o "turismo", inseri-lo como uma atividade que deveria ser desenvolvida pela comunidade, e que os benefícios gerados por ela fossem direcionados principalmente à comunidade.

Após a formalização de Anã no projeto de turismo da ONG PSA e com a seleção do projeto pelo Ministério do Turismo, por meio do Edital n. 001/2008 para financiamento, iniciaram-se as oficinas de qua- 
lificações das comunidades que, como já citamos, além de Anã, havia mais três comunidades envolvidas no projeto.

Antes mesmo do encerramento das capacitações e oficinas realizadas em Anã, a ONG PSA ofereceu à comunidade a possibilidade de receberem um grupo de visitantes, os quais deveriam hospedá-los em suas residências. Seria, segundo o coordenador do projeto, a oportunidade de colocar a teoria em prática, e testá-los de fato como anfitriões. Então, em novembro de 2008, receberam um grupo de 10 a 15 estudantes americanos, que ficaram hospedados durante uma semana nas casas das famílias, convivendo e compartilhando o cotidiano delas. A vinda desse grupo foi feita por meio de uma Organização Internacional, que possibilitava aos jovens um período de experiência na Amazônia. Parceria esta que se mantém até os dias atuais com a ONG PSA (POMPERMAIER, 2014).

Observa-se, a partir disso, que a ONG atua também como um intermediador entre os visitantes e a comunidade. No início do projeto essa intermediação era bem forte; atualmente, a própria comunidade dá início a um processo de intermediadora, contudo, ainda, a ONG apresenta-se como principal interlocutora nesse processo. Aliás, em vários processos que envolvem o projeto de turismo de base comunitária, como veremos mais adiante.

Após a primeira fase de qualificações e ao passar pelo primeiro teste ao receber o grupo de estudantes norte-americanos, percebeu-se que Anã encontrava-se preparada para a recepção de outros visitantes. Assim iniciou-se uma nova fase em que Anã, assim como em outras comunidades envolvidas no projeto, que também começaram a receber visitantes. A ONG PSA passou a executar o roteiro proposto apresentado em seu projeto, o qual correspondia à visitação nas 4 (quatro) comunidades participantes deste, as quais foram: Anã, Atodí, Arimum e Vila Amazonas. O roteiro tinha a duração de 5 (cinco) dias, geralmente o tempo em cada comunidade correspondia a um (1) dia, no qual percorriam os projetos, realizavam refeições, compartilhavam experiências com os visitantes por meio das rodas de conversas, momento este em que os visitantes e os comunitários trocavam conhecimentos.

No caso mais específico de Anã, os visitantes poderiam ir ao projeto de criação de peixes, projeto Melipomel (Manejo de Abelhas sem ferrão), além de terem uma refeição, esta concretizada através de uma Piracaia.

Após um período realizando esse tipo de roteiro, em suas avaliações, a ONG com as comunidades, começaram a perceber a necessidade de encontrar outra forma de levar visitantes às comunidades, que possibilitasse a ampliação de benefícios a estas, uma vez que o tipo de pacote oferecido às pessoas, ao utilizar o barco para percorrer as 4 (quatro) comunidades durante 5 (cinco) dias, encarecia o custo da viagem, deixando uma renda baixa para a comunidade, tendo em vista o custo alto com a locação da embarcação, compra de diesel, tripulação do barco (comandante, marinheiro, cozinheiro), além de mediadores culturais da ONG PSA, impedindo dessa forma, conforme assinalou o coordenador do projeto, uma transferência maior de renda à comunidade.

Diante disso, a ONG PSA, com as comunidades, mais especificamente Anã, começou a pensar na possibilidade de criar uma pequena infraestrutura que viesse atender a essas pequenas necessidades. No ano de 2009, deu-se início ao processo de discussão sobre a construção de uma pousada comunitária que, além de possuir uma área que serviria como dormitório, teria uma área para cozinha e banheiros. Apresentou-se assim um projeto de uma hospedaria, tanto para Anã quanto para a outra comunidade, Atodí, comunidades que atualmente apresentam estruturas de hospedagem em seu território. Em Anã, a pousada recebeu o nome de "Hospedaria Comunitária de Anã”, portanto, adotaremos o termo hospedaria. 
A construção da hospedaria começou de fato no ano 2013, sendo construído, primeiramente, o redário e, posteriormente, uma parte dos banheiros, concluindo-os ainda no mesmo ano, sendo já possível receber pessoas para pernoitar na comunidade. O local onde os visitantes faziam refeições ainda permanecera na praia da comunidade, pois a construção do refeitório da hospedaria ainda não havia iniciado, a bem como faria parte da próxima etapa de construção da hospedaria.

Logo após a finalização da construção do redário e dos banheiros, iniciou a outra fase do projeto, a construção da cozinha e do refeitório, pois no final do ano de 2013 conseguiram recursos de outro órgão financiador. Até setembro de 2014, foi arrecadado e empregado na construção da hospedaria um valor de $\mathrm{R} \$ 160.000,00$ (cento e sessenta mil reais).

Em setembro de 2014 o projeto da hospedaria comunitária de Anã estava praticamente todo concretizado, toda a estrutura finalizada, redário, banheiros, cozinha e refeitório, estes dois últimos também foram mobiliados.

É necessário ressaltar que quando se fala em comunidade de Anã, partimos da referência do território de Anã, porém, nem toda a comunidade é envolvida ativamente no projeto. Até setembro de 2014, das 96 famílias existentes em Anã, participavam de forma direta e indireta aproximadamente 30 famílias, entre as quais aquelas participando de forma direta na recepção dos visitantes, realização das refeições, e aqueles que participam vendendo seus produtos para atender à demanda de visitantes, principalmente no que se refere aos produtos utilizados no preparo das refeições, como a galinha caipira, o peixe, hortaliças e frutas para o preparo do suco.

Diante do exposto, podemos perceber que a atuação da ONG PSA em Anã se consolidou com o projeto de Ecoturismo de Base Comunitária (EBC) que esta desenvolve na comunidade desde o ano de 2008. Apesar de sua atuação anterior, com projetos ligados ao seu programa de Saúde, a implementação do projeto de EBC em Anã configurou uma nova relação entre a ONG e a comunidade. Atualmente, a atuação da ONG na comunidade não se restringe apenas ao projeto de EBC; paralelo a esse projeto, há outros projetos em desenvolvimento, como o caso do projeto do viveiro.

Além de atuar como principal intermediadora para a vinda dos visitantes à comunidade de Anã, a ONG PSA estabelece ainda algumas funções aos comunitários envolvidos com o projeto, entre as quais cita-se a escolha da "gerente" da hospedaria, que fica responsável pela gerência desta e também por indicar a "chefe" da cozinha no dia em que há grupo de visitantes. A ONG assume de certa forma um papel de agenciadora, conforme menciona a presidente da associação de Anã, ao relatar sua preocupação na urgência em regulamentar a hospedaria, para que possam efetuar pagamentos às pessoas que prestam serviço para a pousada e emissões de notas fiscais aos visitantes.

Em relação ao Estado, identificamos que este pouco ou quase nada despende ações para o desenvolvimento do turismo de base comunitária em Anã. Como ressaltado anteriormente, Anã está localizada em uma unidade de conservação, denominada Reserva Extrativista Tapajós-Arapiuns. Assim como as demais comunidades localizadas na Resex, Anã recebe poucas ações do Estado, seja este em nível municipal, estadual e federal.

Contudo, não podemos considerar o Estado ausente em Anã, uma vez que foram identificadas ações concretas do poder municipal e federal na comunidade, no entanto, em áreas como educação, saúde e habitação, em relação ao turismo, podemos considerar o Estado em todas as esferas praticamente ausente, tendo em vista que foram desenvolvidas ações pontuais em Anã, e com mais destaque a atuação do Go- 
verno Federal, conforme já mencionado, por meio do recurso advindo do Ministério do Turismo em 2008 em decorrência do Edital de Chamada Pública de Projetos MTur/N. 001/2008.

Para identificarmos como ocorreu e se ocorre essa atuação do Estado em Anã, além de realizarmos entrevistas com os comunitários desta e o coordenador do projeto de TBC da ONG PSA, fizeram parte como sujeitos desta parte da pesquisa duas pessoas que foram secretários de Turismo do município de Santarém, respectivamente entre os anos 2009-2011 e 2011-2012, além de entrevistarmos também a pessoa que até então correspondia à secretária de Turismo do município, porém, esta permanecera como secretária até março de 2015. Realizamos ainda a análise de documentos, como Plano de Marketing Destino Referência em Ecoturismo Santarém/PA (2012); Plano de Desenvolvimento Turístico do Estado do Pará (2001); Plano Estratégico de Turismo do Estado do Pará (2012-2020); e o Plano de Manejo da Resex Tapajós-Arapiuns (2014).

Buscamos a partir das análises de tais documentos, identificar em que medida se deu e tem se dado as ações do Estado para o desenvolvimento do TBC em Anã e nossas análises nos levaram à conclusão de que tais documentos não contemplam tal experiência. Porém, dois documentos fazem referência ao projeto de ecoturismo de base comunitária desenvolvido pela ONG PSA, sendo predominante a atuação dessa entidade, como enfatizado a seguir.

O Plano de Marketing - Destino Referência em Ecoturismo - Santarém/PA foi elaborado a partir de uma exigência apresentada no diagnóstico do planejamento estratégico já desenvolvido no município, e fundamental para o desenvolvimento do "Projeto Fortalecimento do Destino Referência em Ecoturismo - Santarém/PA". Nesse Plano de Marketing, identificamos que é apontado o Projeto de "Turismo de Base Comunitária" da ONG PSA que dá foco nas comunidades. Nesse sentido, a atuação da ONG PSA é apontada como um ponto forte para estruturação da oferta e divulgação do destino turístico.

Quanto ao Plano de Desenvolvimento Turístico do Estado do Pará (2001) e ao Plano Estratégico de Turismo do Estado do Pará (2012-2020), ambos não fazem referência ao projeto desenvolvido pela ONG. Contudo, o Plano Estratégico de Turismo do Estado do Pará apresenta algumas ações a serem realizadas em comunidades tradicionais, porém, nada relacionado à comunidade de Anã, nem ao projeto de turismo de base comunitária desenvolvido pela ONG PSA nas comunidades ribeirinhas da Resex Tapajós-Arapiuns.

Em nossas pesquisas analisamos ainda o Plano de Manejo da Resex Tapajós (2014), o qual tivera o ICMbio como responsável pela sua elaboração, em parceria com outras instituições. No Plano é citado o projeto de turismo desenvolvido em Anã como parte da caracterização econômica da Resex, apontando-o como "uma prática mais próxima do Turismo de Base Comunitária - TBC" (ICMBIO, 2014). Contudo, não identificamos nenhuma ação voltada para o projeto desenvolvido em Anã, embora este apresente o turismo como uma alternativa de renda para outras comunidades da Resex. No que se refere ao âmbito municipal, não encontramos documentos que pudessem nos auxiliar em nossas análises, pois a Secretaria de Turismo ainda está trabalhando na elaboração do Plano Municipal de Turismo. Identificamos, todavia, que não há ações para o projeto que tem sido desenvolvido em Anã. Se levarmos em consideração o ano de implementação do projeto pela ONG PSA na comunidade, ano de 2008, até o ano de 2014 não houve qualquer tipo de ação voltada para essa prática em Anã.

A ONG PSA, com alguns comunitários de Anã, participaram de algumas reuniões realizadas pela Secretaria de Turismo no período de discussão da construção do Plano de Marketing - Destino referência 
em ecoturismo Santarém/PA (2012), porém, foram participações pontuais e voltadas de forma específica à construção do Plano de Marketing, e essa participação também se deu pelo fato da ONG PSA ser membro do Grupo Gestor do Turismo de Santarém.

Conforme ressaltamos anteriormente, de 2008 até 2014, não houve qualquer forma de ação por parte do Estado no que se refere às esferas municipal e estadual. No que tange à atuação do Estado em nível federal, identificamos apenas o Edital n. 001/2008 do Ministério do Turismo, que direcionou uma verba de $147.766,50$ (cento e quarenta e sete mil e setecentos e sessenta e seis reais e cinquenta centavos) ao projeto de ecoturismo de base comunitária que fora submetido pela ONG PSA contemplando, além de Anã, três comunidades envolvidas no projeto.

De acordo com o coordenador do projeto de turismo de base comunitária desenvolvido em Anã, além do recurso advindo do Ministério do Turismo, não houve qualquer outra forma de manifestação do Estado para com o projeto de turismo de base comunitária, seja em Anã ou em outras comunidades. A ONG procurou algumas vezes articular e solicitar algumas ações por parte dessa entidade, porém, não foram exitosas, até pelo fato da falta de objetividade do Estado em suas ações, bem como da urgência em realizar e consolidar o projeto de TBC nas comunidades, mais especificamente em Anã, principalmente no período de construção da hospedaria, que houve uma maior necessidade de captação de recursos. Porém não descarta a possibilidade de parcerias com este.

Assim como o coordenador do projeto, os comunitários entrevistados em Anã desconhecem qualquer forma de atuação por parte do Estado em relação ao turismo na comunidade. Dos 19 (dezenove) entrevistados, somente três afirmaram que não há atuação efetiva do poder público seja local e/ou estadual, ante o turismo, os demais não sabem informar se há ou não qualquer forma de atuação. Contudo, identificamos que um dos órgãos que têm auxiliado a comunidade em alguns momentos é o Instituto Chico Mendes de Conservação da Biodiversidade (ICMbio), conforme podemos observar abaixo:

[...] este poder público nosso aqui que está zerado... O municipal não forneceu nenhum prego sequer.... não, não ainda não veio. [...] Do estadual até agora também só tem promessas... Onde a gente tem um apoio, e colaboração, ainda não veio em dinheiro, mas vem através de não medir esforços pra documentos, pra licenciar, pra divulgar, pra emitir documentos. O ICMBio é um órgão que a gente, que tá junto com a gente, a gente pode contar com ele... [...] Então o poder público, onde e quando a gente encontra o apoio, e precisa de verdade, é no federal, é no gestor da unidade de conservação... (GODINHO, 2014).

Diante disso, identificamos a pouca ou quase nula atuação do poder público local e estadual; o federal se faz presente por meio do ICMbio, este que é o gestor da Resex e, mediante algumas ações, tem auxiliado o desenvolvimento do projeto de TBC como apontado por Godinho (2014).

Como ressaltamos, o projeto de TBC existe em Anã desde o ano de 2008 e, ao longo desse período, assim como apontado pelo coordenador do projeto, e um dos comunitários de Anã, não houve qualquer forma de atuação efetiva do poder público estadual em relação ao turismo. Na esfera municipal, podemos constatar esse fato também nas entrevistas realizadas com os ex-secretários de Turismo e com a pessoa que estava à frente da Secretaria no período de realização desta pesquisa (2013-2015); apesar de estes terem conhecimento do projeto de TBC desenvolvido pela ONG PSA nas comunidades ribeirinhas de Santarém, durante o período de gestão dos mesmos não foi programada qualquer tipo de ação para a comunidade, como poderemos ver a seguir.

O órgão responsável pelo turismo no município de Santarém durante o período que realizamos o trabalho foi a Secretaria Municipal de Turismo. Em março de 2015 o órgão foi reestruturado e o turismo passou a ser vinculado à Secretaria Municipal de Desenvolvimento e Turismo. 
As entrevistas realizadas apontaram que a atuação do Estado, no que refere ao poder público municipal de Santarém, desde o período em que se iniciou o projeto em 2008, até o ano de 2014, não houve ações efetivas e direcionadas à comunidade ribeirinha de Anã, no que tange ao TBC desenvolvido sob a coordenação da ONG PSA. Identificamos que tanto os ex-secretários como a secretária que estava à frente da Secretaria de Turismo durante o ano de 2014 reconhecem a importância do projeto que a ONG tem desenvolvido, assim como apontam a relevância da ONG nessas comunidades, principalmente quando observam a efetivação dos projetos nas comunidades ribeirinhas.

Como não foram solicitadas ações por parte da ONG, assim como pela comunidade Anã à Secretaria de Turismo, esta também não manifestou interesse em colaborar com ações efetivas ao projeto implementado em Anã. A ONG apresenta um grau de independência, principalmente no que se refere aos projetos e sua atuação nas comunidades ribeirinhas, que leva de certa forma à atenuação da atuação do poder público em tais comunidades, principalmente no que se refere à comunidade de Anã, nosso local de estudo.

Claro que não podemos falar do desenvolvimento do TBC sem ressaltar as ações que este realiza nas áreas citadas acima, pois o sucesso no caso do projeto de TBC depende também da implementação de boas políticas em tais áreas, contudo, a comunidade tem a necessidade de ter alternativas de geração de renda compatíveis com o permitido para uma unidade de conservação e, principalmente, compatível com o seu cotidiano.

O Estado, nos níveis municipal, estadual e federal, mostra-se em certa medida ausente presente, pois atribuiu de forma indireta a responsabilidade do desenvolvimento do turismo de base comunitária em Anã para a ONG PSA, sendo esta financiada em certa medida por recursos do Estado, como o caso do recurso advindo do Ministério do Turismo no ano de 2008 para o financiamento do projeto de turismo de base comunitária.

\section{CONSIDERAÇÕES FINAIS}

Atualmente, Anã tem se destacado como uma das comunidades da Resex que mais têm empreendido projetos, ressaltando a eficácia destes para a comunidade. Entre tais projetos, destacamos neste trabalho o projeto de TBC, o qual tem sido desenvolvido em parceria com a ONG PSA desde o ano de 2008, período este que marca o início da forte atuação da ONG PSA na comunidade de Anã.

Contudo, vale ressaltar que anteriormente ao envolvimento de Anã com o projeto de TBC coordenado pela ONG PSA, Anã, mesmo sem saber e, consequentemente, sem dar autorização, fazia parte de roteiros de agências de turismo de Santarém, as quais levavam visitantes para conhecer os projetos existentes, e não contribuíam com a comunidade, pelo contrário, deixavam apenas lixo. Diante disso, as lideranças da comunidade começaram a mobilizar-se e a buscar informações de como poderiam desenvolver o "turismo" na comunidade. Foi este o ponto de partida para alguns comunitários iniciarem a saga por esclarecimentos acerca do turismo. Nesse contexto, iniciaram seus primeiros contatos em relação ao turismo com a ONG PSA, pois conforme apontamos, a ONG já desenvolvia ações do seu programa "Saúde Comunitária".

Em nossa pesquisa, partimos do entendimento do turismo de base comunitária enquanto um contra-movimento, uma racionalidade contra-hegemônica, que diante dos ditames da lógica racional do turismo convencional, busca reavivar valores, encontros entre o Eu e tu (Martin Bubber), e proclamar a desalienação, adormecidos no atual período técnico-científico e informacional. 
Pelo que analisamos, as decisões tomadas em relação ao TBC na comunidade centralizam-se no grupo de turismo, assim como na ONG PSA, sendo que esta última configura-se como principal agente hegemônico do turismo na comunidade, intermediando a ida dos grupos a esta, selecionando os visitantes, uma vez que aplica um questionário para identificar se a pessoa que se predispõe a conhecer não somente Anã, mas outras comunidades que desenvolvem o projeto de TBC tem o perfil adequado, já que, como revelado, é uma viagem diferenciada. A ONG, identificada como agente hegemônico no processo, é um dos agentes responsáveis pela divisão das funções entre as pessoas que compõem o grupo de turismo.

Com base em nossas análises, identificamos que a ONG PSA foi e é determinante para a implantação e continuidade do projeto em Anã. Apesar da invocação contínua do termo comunidade ao referir-se à experiência de TBC em Anã, das 96 famílias existentes, 30 famílias participam do projeto, porém, uma parcela da renda gerada por este é destinada à Associação da Comunidade, sendo assim, o projeto tem alcançado direta e indiretamente as famílias. Contudo, há comunitários que não têm conhecimento dessa renda que é direcionada à associação, assim como aqueles que revelam que nunca viram o emprego do dinheiro do TBC em melhorias para a comunidade. A participação dos comunitários no projeto de TBC se dá principalmente na cozinha da hospedaria, pois é onde se concentra uma maior demanda de tarefas a serem executadas durante a presença dos visitantes. Há dois comunitários que lideram o grupo de turismo, organizando-o para os dias em que haverá visitantes na comunidade. Tais comunitários são geralmente os que discutem com a ONG PSA o desenvolvimento e organização do projeto de TBC, contudo, mais uma vez, foi possível identificar que a ONG ainda detém maior hegemonia nas discussões em relação ao projeto de TBC.

Apesar da consolidação e evidência do projeto de TBC coordenado pela ONG PSA no município de Santarém, identificamos que houve poucas manifestações do Estado em prol deste, reveladas principalmente e unicamente por ações no âmbito nacional, como a contemplação do projeto de TBC no ano de 2008 pelo Edital n. 001/MTur, além da atuação do ICMBio, que viabilizou autorizações à comunidade para a construção da hospedaria comunitária.

No que se refere às ações no âmbito estadual, constamos a inexistência de tal, assim como em seus planos, não foram identificadas ações nesse sentido que pudessem contemplar o TBC em Anã, ou no próprio município de Santarém. Contudo, identificamos que o Governo estadual se faz presente na comunidade por meio do Sistema Modular de Ensino Médio. Constatamos ainda, no que se refere a outros programas da ONG, que esse nível de Estado foi parceiro da ONG PSA entre os anos 2012 e 2013, porém, nada relacionado ao projeto de TBC.

Na esfera municipal, identificamos que esta atua nas áreas de educação e saúde, porém, o órgão responsável pelo turismo no município não havia, até setembro de 2014, realizado, nem planejado ações para o projeto de TBC em Anã, considerando a ONG avançada e organizada nessa questão e, portanto, sendo desnecessária uma ação efetiva da Secretaria, até pelo fato de serem escassos os recursos financeiros desta, inviabilizando assim uma maior atuação no município. Consideram ainda a autossuficiência da ONG na execução desse projeto, bem como a proteção desta em relação aos projetos que desenvolve, assim como em relação às comunidades em que é atuante, como no caso de Anã.

Diante disso, consideramos que a ONG PSA assume papel hegemônico na implementação de ações que conduzem ao desenvolvimento territorial das comunidades ribeirinhas contempladas com seus projetos. Constitui-se como um ator crucial para tais comunidades, realizando ações muito mais efetivas do que o próprio Estado. O Estado por outro lado, considerando a presença da ONG, mais especificamente 
em relação ao turismo de base comunitária, e tratando-se do Estado em âmbito municipal, considera desnecessário o direcionamento de ações para Anã, uma vez que a ONG vem desempenhando com êxito seu trabalho.

Levando em consideração a presença hegemônica da ONG PSA na produção do espaço para o turismo de base comunitária em Anã, não é possível neste momento apontá-la como uma contrarracionalidade hegemônica, assim como as lacunas existentes entre o grupo de comunitários que são envolvidos com o TBC e os comunitários que não são envolvidos. Ainda que, é possível identificarmos o elemento econômico sobrepondo-se à comunidade, tendo em vista a desconfiança que é gerada em decorrência do valor que é repassado do projeto de TBC à associação dos comunitários que, assim como a forma de gestão da hospedaria comunitária, tem sido a causa de descontentamentos de certos comunitários.

Apesar da atuação da ONG como agente hegemônico no processo, não podemos deixar de considerar a atuação do Estado em Anã. Como apontamos, em relação ao TBC, tanto em nível estadual como em nível municipal poucas ações ou nenhuma ação foram direcionadas ao projeto. No que se refere ao Estado, em nível federal, as ações mostraram-se pontuais, contudo, se configuram como uma ausência presente do Estado, pois por meio do Edital do Mtur n. 001/2008, financiou o projeto de TBC desenvolvido pela ONG PSA.

Contudo, constatamos que, para além de uma ausência presente do Estado, se faz necessária uma maior atuação desse agente em relação ao TBC em Anã, principalmente em nível municipal, levando em consideração a localização da comunidade, pois, conforme apontamos, durante os 7 (sete) anos de existência do projeto, em nenhum momento ocorreu uma visitação à comunidade de Anã para conhecimento do projeto, bem como um planejamento de ações em parcerias com a ONG PSA ou com a própria comunidade.

Por mais que a ONG apresente uma autonomia quanto as suas ações na comunidade, não podemos deixar de prescindir o papel e a importância do Estado no TBC desenvolvido em Anã. Além do que, é a partir do reconhecimento de experiências como essa, que será possível a elaboração de políticas públicas específicas a essa modalidade de turismo, bem como pautadas nas especificidades das populações tradicionais ou não, que buscam, por meio do TBC, alternativas de geração de renda, permanência e o desenvolvimento de seus territórios.

\section{REFERÊNCIAS}

BARTHOLO, R. Sobre o sentido da proximidade: implicações para um turismo situado de base comunitária. In: BARTHOLO, R; BURSZTYN, I; SANSOLO, D. Turismo de Base Comunitária: diversidade de olhares e experiências brasileiras. Ed. Letra e Imagem, 2009.

BURSZTYN, I. Desatando um nó na rede: sobre um projeto de facilitação do comércio direto do turismo de base comunitária na Amazônia. - Rio de Janeiro: UFRJ/COPPE, 2012. VIII, 243 p.: il.; 29,7 $\mathrm{cm}$. Orientador: Roberto dos Santos Bartholo Júnior. Tese (Doutorado) - UFRJ/COPPE/Programa de Engenharia de Produção, 2012.

CORIOLANO, L. N. O turismo comunitário no nordeste brasileiro. Turismo de Base Comunitária: diversidade de olhares e experiências brasileiras. Ed. Letra e Imagem, 2009, p. 277-288. 
COUTINHO, J. A. ONGs: caminhos e (des)caminhos. Lutas Sociais (PUC-SP), São Paulo, v. 13/14, p. 5765,2005 .

CRUZ, R. de C. A. Introdução à Geografia do turismo. 2. ed. São Paulo. Roca, 2003.

Políticas públicas de turismo no Brasil: território usado, território negligenciado. In: Geosul, Florianópolis, v. 20, n. 40, p. 27-43, jul./dez. 2005.

Planejamento governamental do turismo: convergência e contradições na produção do espaço. In: LEMOS, A. I. G. de; ARROYO, M. América Latina: cidade, campo e turismo. San Pablo: Clacso, 2006, p. 337-350.

. Turismo, produção do espaço e desenvolvimento desigual: para pensar a realidade brasileira. In: BARTHOLO, R; BURSZTYN, I; SANSOLO, D. Turismo de Base Comunitária: diversidade de olhares e experiências brasileiras. Ed. Letra e Imagem, 2009, p. 92-107.

HARVEY, D. O novo imperialismo. 7. ed. São Paulo: Edições Loyola, 2013.

. A produção capitalista do espaço. São Paulo: Annablume, 2005.

INSTITUTO CHICO MENDES DE CONSERVAÇÃO DA BIODIVERSIDADE. Plano de Manejo da Reserva Extrativista Tapajós-Arapiuns. ICMBio, Santarém, 2014.

IRVING, I. Reinventando a reflexão sobre turismo de base comunitária. In: BARTHOLO, R; BURSZTYN, I; SANSOLO, D. Turismo de Base Comunitária: diversidade de olhares e experiências brasileiras. Ed. Letra e Imagem, 2009, p. 108-121.

LANDIM, L. A invenção das ONGs: do serviço invisível à profissão impossível. (Tese de Doutorado) Programa de Pós-Graduação em Antropologia Social do Museu Nacional e da Universidade Federal do Rio de Janeiro. Rio de Janeiro, 1993. Disponível em: 〈http://empreende.org.br/pdf/ONG\%275,\%20 OSCIP\%27S\%20e\%20Terceiro\%20Setor/A\%20i nven\%E7\%E30\%2odas\%20ONGs.pdf $>$. Acesso em: Ago. 2014.

MALDONADO, C. Fortaleciendo redes de turismo comunitário. In: @local.glob - n. 4, 2007, p. 8-14.

O turismo rural comunitário na América Latina: gênesis, características e políticas. In: BARTHOLO, R; BURSZTYN, I; SANSOLO, D. Turismo de Base Comunitária: diversidade de olhares e experiências brasileiras. Ed. Letra e Imagem, 2009, p. 25-44.

MARIANO, K. P. Globalização, integração e o Estado. In: Lua Nova: Revista de Cultura e Política. Online version ISSN 1807-0175. Lua Nova n. 71, São Paulo, 2007.

MITRAUD, S. (Org.). Manual de ecoturismo de base comunitária: ferramenta para um planejamento responsável. Brasília, DF: WWF Brasil, c 2003.

PARÁ. Governo do Estado. Ações para o incremento do turismo no Estado do Pará. Belém: PARATUR; THR, 1998.

. Governo do Estado. Plano de desenvolvimento do turismo do estado do Pará (PDT-PA). Belém: PARATUR; THR, 2001.

. Governo do Estado. Plano Estratégico de Desenvolvimento do Turismo do estado do Pará. Belém: PARATUR, 2011.

SANCHO, A; IRVING, M. A. Tendências de inclusão social no Plano Nacional de Turismo 2007/2010: uma interpretação preliminar. Geografias Artigos Científicos. Belo Horizonte, o7(1) janeiro-junho de 2011, p. 44-57. 
SANSOLO, D. Centralismo e participação na proteção da natureza e desenvolvimento do turismo no Brasil. In: BARTHOLO, R; BURSZTYN, I; SANSOLO, D. Turismo de Base Comunitária: diversidade de olhares e experiências brasileiras. Ed. Letra e Imagem, 2009, p. 122-141.

SANSOLO, D; BRUSZTYN, I. Turismo de base comunitária: potencialidade no espaço rural brasileiro. In: BARTHOLO, R; BURSZTYN, I; SANSOLO, D. Turismo de Base Comunitária: diversidade de olhares e experiências brasileiras. Ed. Letra e Imagem, 2009, p. 142-161.

SANTOS, M. Metamorfoses do espaço habitado. São Paulo: Hucitec, 1991.

A natureza do espaço: técnica e tempo, razão e emoção. 4. ed. 5 reimp. São Paulo: Edusp, 2009a.

Pensando o Espaço do Homem. 5. ed., 2 reimpr. São Paulo: Editora da Universidade de São Paulo, 2009b.

. Por uma outra globalização: do pensamento único à consciência universal. 18. ed. Rio de Janeiro: Record, 2009c.

. O Espaço do cidadão. 7. ed., 1 reimpr. - São Paulo, 2012a.

2012b.

. Da Totalidade ao Lugar. 1. ed., 2 reimp. São Paulo: Editora da Universidade de São Paulo,

. Por uma Geografia Nova: da crítica da geografia a uma geografia política. 6 ed., 2. reimp. São Paulo: Editora da Universidade Federal de São Paulo, 2012c.

- Da Política dos Estados à Política das Empresas. Disponível em: 〈http://ricardoantasjr. org/wp-content/uploads/2013/05/\%E2\%80\%9CDa-Pol\%C3\%ADticados-Estados-\%C3\%AoPol\%C3\%ADtica-das-Empresas\%E2\%80\%9D.-Milton-Santos.pdf >.

SANTOS, M.; SILVEIRA, M. L. O Brasil: território e sociedade no início do século XXI. Rio de Janeiro: Record, 2008.

TODESCO, C. Estado e produção terceirizada da política pública de turismo para a Amazônia Legal. Tese (Doutorado em Geografia - Geografia Humana) - Universidade de São Paulo, Conselho Nacional de Desenvolvimento Científico e Tecnológico. Orientador: Rita de Cássia Ariza da Cruz. São Paulo, 2013.

. Estado e terceiro setor na organização do espaço para o turismo no Vale do Ribeira. São Paulo: Departamento de Geografia da Faculdade de Filosofia, Letras e Ciências Humanas da USP, 2007 (Dissertação de Mestrado).

ZAOUAL, H. Do turismo de massa ao turismo situado: quais as transições? In: BARTHOLO, R; BURSZTYN, I; SANSOLO, D. Turismo de Base Comunitária: diversidade de olhares e experiências brasileiras. Ed. Letra e Imagem, 2009, p. 55-75. 